Boise State University

ScholarWorks

Counselor Education Faculty Publications and

Presentations

Department of Counselor Education

6-1-2008

Reducing Heavy Drinking in Intercollegiate Athletes: Evaluation of a Web-Based Personalized Feedback Program

Diana Doumas

Boise State University

Tonya Haustveit

Boise State University 


\title{
Reducing Heavy Drinking in Intercollegiate Athletes: Evaluation of a Web-Based Personalized Feedback Program
}

\author{
Diana M. Doumas and Tonya Haustveit \\ Boise State University
}

\begin{abstract}
This study evaluated the efficacy of a Web-based personalized feedback program aimed at reducing drinking in freshman intercollegiate athletes. The program was offered through the Athletic Department freshman seminar at a NCAA Division I university. Seminar sections were randomly assigned to one of two conditions: Web-based personalized feedback (WPF) or Web-based education (WE). Assessment measures were completed at baseline, 6 weeks, and 3 months. Athletes were classified as high-risk or low-risk drinkers based on baseline reports of binge drinking. Results indicated for high-risk athletes, students in the WPF condition reported significantly greater reductions in drinking and changes in beliefs about peer drinking than those in the WE condition. In addition, reductions in drinking were related to reductions in peer drinking estimates for athletes in the WPF group. Findings provide initial support for the efficacy of Web-based personalized feedback for reducing the quantity and frequency of heavy drinking in freshman intercollegiate athletes.
\end{abstract}

Heavy drinking represents a significant problem on college campuses in the United States, with over 30\% of college students meeting the Diagnostic and Statistical Manual of Mental Disorders (DSM-IV; American Psychiatric Association, 2000) criteria for alcohol abuse (Knight et al., 2002). Similarly, national survey data from 14,000 students indicate $44 \%$ of students report binge drinking, defined as 5 or more drinks in a row for males and 4 or more for females, at least once in the past 2 weeks, with $23 \%$ of these reporting binge drinking three or more times in the past 2 weeks (Wechsler, Lee, Kuo, \& Lee, 2000). Alcohol use, heavy drinking, and binge drinking are also associated with multiple social and interpersonal problems such as arguing with friends, engaging in unplanned sexual activity, drinking and driving, getting into trouble with the law, and academic difficulties (Abbey, 2002; Cooper, 2002; Hingson, Heeren, Zakocs, Kopstein, \& Wechsler, 2000; Vik, Carrello, Tate, \& Field, 2000; Wechsler et al., 2000).

Doumas and Haustveit are with the Dept. of Counselor Education, Institute for the Study of Addiction, Boise State University, Boise, ID 83725-1715. 
Relative to the general college population, student athletes have been identified as a high-risk group for heavy drinking (Martens, Dams-O'Connor, \& Beck, 2006; Turrisi, Mallett, Mastroleo, \& Larimer, 2006). Research indicates students participating in athletic activity, including varsity, intramural, and club sports, typically drink more heavily and frequently than nonathletes (Doumas, Turrisi, Coll, \& Haralson, 2007; Hildebrand, Johnson, \& Bogle, 2001; Leichliter, Meilman, Presley, \& Cashin, 1998; Nelson \& Wechsler, 2001) and level of athletic involvement is positively related to levels of heavy drinking (Hildebrand et al., 2001; Leichliter et al., 1998). Although few sex differences in drinking have been found among student athletes (Turrisi et al., 2006), research has identified different prevalence rates and patterns of alcohol use across sports. Survey data indicate high rates of drinking occur in swimming, diving, soccer, baseball, and softball (NCAA, 2001) and athletes participating in swimming and diving report more heavy episodic drinking, drinking days, and drinks per week than other athletes (Martens, Watson, $\&$ Beck, 2006). Intercollegiate athletes also drink more during their off-season than their competitive season (Martens, Dams-O'Connor, \& Duffy-Paiement, 2006; Thombs, 2000).

Several social explanations for the high rates of drinking found in the student athlete population have been proposed (see Martens, Dams-O'Connor, \& Beck, 2006). Recently, peer influence has gained attention in the literature as an important social variable that might be related to the elevated levels of drinking in student athletes. According to social norming theory (Perkins, 2002), college students overestimate the drinking of their peers, believing that their peers drink more than normative data suggest, and this overestimation is related to heavy drinking as students try to match their drinking to that of their peers. In addition, perceived drinking norms for more proximal groups, such as close friends, are more predictive of drinking behavior than perceived norms for more distal groups, such as typical university students (Baer, Stacy, \& Larimer, 2001). Similarly, student athletes also believe their peers, including both typical teammates and typical students on campus, drink more than they do (Thombs, 2000), and this is true both during off- and on-season (Dams-O'Connor, Martin, \& Martens, 2007). Overall, these findings suggest student athletes might drink to match their perceptions of peer alcohol use. Thus, providing accurate feedback to athletes regarding peer drinking might result in a downward adjustment in beliefs about peer drinking and, in turn, a reduction in heavy drinking.

Although alcohol prevention programs have been developed for the collegiate athlete population, few studies have reported efficacy data on actual drinking outcomes. For example, Athletic Prevention, Programming and Leadership Education (APPLE; Grossman, Gieck, Freedman, \& Fang, 1993), a program adopted by over 400 schools nationally (Bruce \& Crockett, 2007), encourages student athletes to participate in prevention efforts and provides principles for seven prevention areas: recruitment practices, departmental expectations and attitudes, education programs, policies, drug testing, sanctioning procedures, and referral and counseling (Bruce $\&$ Sisk, 2006). Although research indicates APPLE Working Weekend conference participants report progress in several prevention areas (Grossman \& Smiley, 1999) and student athlete participants report progress toward learning objectives (Bruce \& Crockett, 2007; Bruce \& Sisk, 2006), results have not included data on the efficacy of APPLE on actual drinking outcomes. 
Despite the importance of program evaluation, to date, only three published studies have evaluated the impact of alcohol intervention programming on drinking outcomes specifically for collegiate athletes (Marcello, Danish, \& Stolberg, 1989; Perkins \& Craig, 2006; Thombs \& Hamilton, 2002). Using an individual-level approach, Marcello et al. (1989) conducted a multicomponent skills-training intervention to reduce drinking in collegiate athletes. The intervention included education, skills training for prevention, and skills to deal with peer pressure. Results indicated there were few differences between the intervention group and control group. The two other published studies evaluated social norms campaigns as an environmental strategy to reduce drinking in collegiate athletes. Thombs and Hamilton (2002) found that 18 months after a campus-wide mass media campaign was implemented, student athletes exposed to the campaign reported lower estimates of drinking, including the percentage of student athletes and nonathletes who binge drink and the typical number of drinks consumed by team captains, team members, and university students, than those not exposed. There were, however, no differences in reported drinking outcomes between the two groups. In contrast, Perkins and Craig (2006) conducted a two-year social norms campaign that included exposure to multiple types of information, including print and electronic mail messages, peer educator programs, and an interactive $\mathrm{CD}$ all providing information about drinking norms. Exposure to the program was assessed by student athlete reports of how often they had read, seen, or used each type of information disseminated. Results indicated exposure to the program was related to a reduction in student athlete reported quantity and frequency of alcohol use. In addition, athletes exposed to the intervention reduced their estimated peer drinking norms, suggesting interventions designed to change drinking estimates might be effective in decreasing drinking among student athletes.

Although there are few published studies examining the efficacy of prevention programs for student athletes, a large body of literature has evaluated programs targeting heavy drinking in college students (see Carey, Scott-Sheldon, Carey, \& DeMartini, 2007; Larimer \& Cronce, 2007). A recent meta-analytic review of the literature on individual-level interventions indicates that college students participating in alcohol interventions reduced their drinking significantly more than participants in control conditions (Carey et al., 2007). Findings indicated these effects lasted up to 6 months, with effects dropping off over longer periods of time. The meta-analysis also demonstrated that interventions using motivational interviewing, a nonconfrontational, nonjudgmental approach designed to decrease drinking and drinking-related consequences (Miller \& Rollnick, 2002), and normative personalized feedback, providing information about one's drinking in relation to actual peer drinking norms, were associated with greater reductions in alcohol-related problems than other types of interventions. Consistent with social norming approaches, providing normative feedback about drinking is associated with a change in alcohol consumption patterns and these changes are mediated by changes in normative perceptions of peer drinking (Neighbors et al., 2004; Walters et al., 2007). That is, receiving personalized feedback is associated with a downward adjustment in students' perceptions of peer drinking that is then related to subsequent decreases in drinking behavior.

Innovative approaches to implementing brief motivational interventions with personalized feedback, including mailed feedback and Web-based feedback, have 
also been developed (see Larimer \& Cronce, 2007). Research indicates several computer courses combining feedback and educational models effectively reduce drinking (e.g., Bersamin, Paschall, Fearnow-Kenney, \& Wyrick, 2007; Chiauzzi, Green, Lord, Thum, \& Goldstein, 2005) and a growing number of controlled studies indicate that delivering brief Web-based personalized feedback, including normative data, is an effective strategy for reducing drinking in college students (Kypri et al., 2004; Neighbors, Larimer, \& Lewis, 2004; Walters, Vader, \& Harris, 2007). Although recent reviews of the literature indicate brief interventions incorporating personalized feedback, whether delivered in person, by mail, or electronically, can be effective in reducing heavy drinking among college students (Larimer \& Crone, 2007), there are many advantages to using computer programs to provide normative feedback to college students (Walters, Miller, \& Chiauzzi, 2005). For example, research indicates young drinkers might respond better to electronic feedback than to in-person feedback (Kypri, Saunders, \& Gallagher, 2003; Saunders, Kypri, Walters, Laforge, \& Larimer, 2004). In addition, whereas college students might be skeptical about discussing their drinking with a health practitioner, they are interested in how their drinking compares with the drinking of their peers. Web-based interventions appeal to this curiosity while reducing the apprehension associated with talking to a professional. Web-based interventions also have the potential both to reach a wide audience and be an engaging medium for students.

Although intercollegiate athletes have been identified as a high-risk population for heavy drinking and research indicates providing personalized feedback is effective in reducing college student drinking, there have been no published studies evaluating personalized feedback programs, either in-person or Web-based, with intercollegiate athletes. Although student athletes might have been included as participants in the above Web-based feedback studies, athletes were not separated from the other students and the effects of the intervention programs on athletes in particular were not examined. Several recent reviews of the literature on college student drinking (Larimer \& Cronce, 2007; Turrisi et al., 2006) and on student athlete drinking in particular (Martens, Dams-O'Connor, \& Beck, 2006) indicate that there is a need for outcome research examining interventions aimed at reducing heavy drinking for student athletes. Martens, Dams-O'Connor, and Beck (2006) also emphasize the importance of determining if intervention programs that are effective with college students might also be effective with collegiate athletes. In addition, as the transition to the freshman year might be particularly difficult for student athletes (Giacobbi et al., 2004), an important area for college program development is providing effective drinking prevention programming for student athletes as they transition into college.

The aim of the current study is to address this gap in the literature by examining the efficacy of a Web-based personalized feedback program (WPF) in reducing heavy drinking in freshman intercollegiate athletes relative to a Web-based education program (WE). As the majority of research examining Web-based programs has demonstrated efficacy in students and young adults identified as high-risk or heavy drinkers (Bersamin et al., 2007; Chiauzzi et al., \& Goldstein, 2005; Doumas \& Hannah, 2008; Kypri et al., 2004; Neighbors et al., 2004; Walters et al., 2007), we also classified student athletes as high-risk or low-risk drinkers using reports of binge drinking at the baseline assessment. The following hypotheses were examined. First, we were interested in examining beliefs about peer drinking and whether 
these beliefs were impacted by the intervention. We hypothesized student athletes would estimate typical student and typical student athlete drinking to be higher than their own drinking. We also predicted that high-risk athletes in the WPF group would reduce their estimates of peer drinking more than those in the WE group. Second, we were interested in examining the efficacy of the WPF intervention in reducing drinking across the fall semester. We hypothesized that high-risk athletes in the WPF group would report greater reductions in drinking compared with those in the WE group. Third, we were interested in the relationship between changes in peer drinking estimates and changes in drinking. We hypothesized changes in estimates of peer drinking would be related to changes in drinking in the WPF group but not in the WE group.

\section{Method}

\section{Participants}

Intercollegiate athletes were recruited from the Athletic Department at a NCAA Division I university in the northwest. The program was offered as part of the athlete freshman seminar curriculum provided by the Athletic Department. All freshman intercollegiate athletes enrolled in the freshman seminar were given an opportunity to participate in the study and participants were not offered compensation. All participants were informed of the nature of the study, risks and benefits of participation, and information regarding the voluntary nature of participation. All participants were treated according to established APA ethical standards and the research was approved by the University Institutional Review Board.

Three seminar sections ( $n=11,23$, and 25) were randomly assigned to either a web-based personalized feedback intervention (WPF) or a web-based education (WE) group. Thirty-four (58\%) student athletes were assigned to the WPF condition and $25(42 \%)$ were assigned to the WE condition. Of these 59 eligible participants, seven were not present in class for the baseline assessment and were not included in the study resulting in a final sample of 52 athletes with $28(54 \%)$ in the WPF condition and $24(46 \%)$ in the WE condition.

For the final sample $(N=52), 58 \%$ of the participants were male and $42 \%$ were female. Ages of the student athletes ranged from 18 to $20(M=18.10, S D$ $=0.61$ ). Fifty-four percent were Caucasian, 27\% African-American, $11 \%$ other, $6 \%$ Asian-American, and 2\% Hispanic. For sport played, 27\% reported football $(n=14), 21 \%$ track $(n=11), 17 \%$ gymnastics $(n=9), 12 \%$ basketball $(n=6), 8 \%$ wrestling $(n=4), 6 \%$ golf $(n=3), 6 \%$ soccer $(n=3), 2 \%$ tennis $(n=1)$. A series of chi square analyses confirmed there were no differences in gender, $\chi^{2}=1.08, p$ $=.40$, ethnicity, $\chi^{2}=6.11, p=.19$, or sport played, $\chi^{2}=3.10, p=.88$, across the two intervention groups. We also compared baseline drinking measures between the two intervention groups and across the three seminar sections to examine initial differences in drinking. A series of independent sample $t$ tests indicated no differences in baseline weekly drinking, $t(50)=0.01, p=.99$, peak drinking, $t(50)$ $=0.24, p=.81$, or drinking to intoxication, $t(50)=0.35, p=.73$, across the two intervention groups. Similarly, a series of one-way ANOVAs indicated no difference 
in baseline weekly drinking, $F(2,49)=0.60, p=.55$, peak drinking, $F(2,49)=$ $1.81, p=.18$, or drinking to intoxication, $F(2,49)=0.76, p=.47$, across the three seminar sections.

\section{Measures}

Alcohol Consumption. Recommendations by the NIAAA Task Force include assessing patterns of alcohol consumption and including at least three measures of consumption covering quantity, frequency, and heavy use (NIAAA, 2003). We included three measures of alcohol use typically used in studies of college drinking: drinking quantity, peak consumption, and frequency of drinking to intoxication. Typical weekly drinking was assessed using a modified version of the Daily Drinking Questionnaire (DDQ, Collins, Parks, \& Marlatt, 1985) in which participants were asked, "Given that it is a typical week, please write the number of drinks you probably would have each day." A response scale is provided for each day of the week (e.g., Monday_, Tuesday_, etc.). Weekly drinking was calculated by combining the reports for the seven days of the week. Peak drinking quantity was assessed by an item asking the participants to indicate the number of drinks consumed on the occasion on which they drank the most in the previous month. Frequency of drinking to intoxication was assessed by the question "During the past 30 days (about 1 month), how many times have you gotten drunk, or very high from alcohol?" This item was rated on a 6-point scale with anchors $0,1-2,3-4$, 5-6, 7-8, or $>9$ times.

We also asked participants to report on the frequency of binge drinking. Binge drinking was defined as having 5 or more drinks in a row for males (4 or more for females) in the past 2 weeks (Wechsler, Davenport, Dowdall, Moeykens, \& Castillo, 1994). This item was used as an indicator of high-risk drinking and was used to create a risk variable, with participants indicating one or more occasions of binge drinking in the past 2 weeks at the baseline assessment classified as high-risk drinkers. The 5/4 binge drinking measure has been widely used and supported as an appropriate threshold to identify high-risk drinkers (Wechsler \& Nelson, 2001; 2006) and identified as a dangerous level of drinking (NIAAA, 2004). Using this measure, $36.5 \%$ of the participants were classified as high-risk drinkers $(39 \%$ in the WPF group; $33 \%$ in the WE group) and $63.5 \%$ were classified as low-risk drinkers (61\% in the WPF group; $67 \%$ in the WE group).

Perceptions of Peer Drinking. Beliefs about peer weekly drinking quantity for typical college students and collegiate athletes were assessed using a modified version of the Daily Drinking Questionnaire (DDQ, Collins et al.,1985). Rather than being asked about their own drinking, participants were given two items in which they were asked to estimate the number of drinks they believe a typical college student and a typical collegiate athlete would drink, "Given that it is a typical week, please write the number of drinks you believe a typical college student (typical collegiate athlete) probably would have each day." A response scale is provided for each day of the week (e.g., Monday , Tuesday , etc.). Weekly estimates of typical college student and collegiate athlete drinking were each calculated by combining the reports for the seven days of the week. 


\section{Interventions}

Web-Based Personalized Feedback Condition (WPF). Participants in the WPF condition completed a 15 min Web-based program designed to reduce high-risk drinking by providing personalized feedback and normative data regarding drinking and the alcohol-related risks. The program is free to the public and is available at http://notes.camh.net/efeed.nsf/newform (for a full description of the program, see Cunningham, Humphreys, \& Koski-Jannes, 2000). An updated version of this program is now available at www.CheckYourDrinking.net. The online assessment collects basic demographic information and information on alcohol consumption, drinking behavior, and alcohol-related consequences. Personalized graphed feedback is provided immediately in the following domains: A pie chart depicting individual levels of drinking in relation to national peer norms, a summary of the number of days the participant consumed alcohol and number of drinks consumed in the past year, approximate financial cost of drinking in the past year, calories associated with drinking, how quickly the body processes alcohol, risk-status for negative consequences associated with drinking and risk-status for problematic drinking based on the participant's Alcohol Use Disorders Identification Test (AUDIT) score.

Web-Based Education Condition (WE). Participants in the WE group were directed to an alcohol education Web site. The Web site is free to the public and is available at http://www.radford.edu/ kcastleb/toc.html. Participants were asked to "surf" the Web site for $15 \mathrm{~min}$. The Web site consists of facts about alcohol and alcohol consumption and guidelines about how to deal with someone who has had too much alcohol to drink.

\section{Procedure}

All participants were given drinking questionnaires at baseline (the first week in September), 6 week (mid-October), and 3 month (first week in December) followup assessments. Research on Web-based interventions has used many timeframes for follow-up assessments including 8 weeks and 16 weeks (Walters et al., 2007), 6 weeks and 6 months (Kypri et al., 2004), and 3 months and 6 months (Neighbors et al., 2004). We selected two time points to capture drinking reports during the semester as previous research examining Web-based personalized feedback indicates early intervention effects may dissipate over time (Walters et al., 2007). Six weeks and 3 months were chosen as they are the midpoint and end of the fall semester. Participants were also asked about their beliefs about typical student athlete drinking and typical college student drinking during the baseline assessment both before the intervention and immediately following the intervention. Estimates of peer drinking were collected immediately after the intervention so that changes in beliefs about peer drinking could not be attributed to environmental factors outside of the intervention or subsequent changes in drinking.

All questionnaires at baseline and follow-up assessments were completed in pen-and-paper format. During the baseline data collection, students were assigned a personal code that was used to identify pre- and postintervention responses from 
each student, as well as to calculate response rates from baseline to follow-up assessments. After completing questionnaires, participants in the WPFG group completed the 15-min online intervention and participants in the WE group "surfed" the educational website for $15 \mathrm{~min}$.

\section{Results}

We first examined the data for extreme cases that might impact the results of the analyses. Extreme cases were defined as those that were more than three standard deviations from the mean on any of the peer drinking beliefs or self-reported drinking measures at baseline. This resulted in eliminating one study participant, resulting in a final sample size of 51 athletes.

\section{Perception of Peer Drinking}

Baseline reports for self, typical collegiate athletes, and typical college student drinking indicated freshman student athletes reported drinking fewer drinks per week $(M=3.96, S D=6.43)$ than they believed a typical collegiate athlete drinks $(M=9.24, S D=7.80)$ and a typical college student drinks $(M=17.31, S D=9.75)$. A series of paired $t$ tests indicated significant differences between self report and report of a typical collegiate athlete, $t(49)=-5.61, p<.001$, self report and report of a typical college student, $t(49)=-9.36, p<.001$, and report of a typical collegiate athlete and a typical college student, $t(49)=6.37, p<.001$. As predicted, results suggest that freshman athletes reported higher levels of weekly drinking for both collegiate athletes and college students than they reported for themselves.

\section{Changes in Perceptions of Peer Drinking}

To examine differences in beliefs about peer drinking from baseline to postintervention reports, we conducted two repeated measures analyses of variance (ANOVA). The three independent variables in the analysis were Time (baseline; postintervention), Group (WPF; WE), and Drinking Risk-Status (high-risk; low-risk). The dependent variables in the two analyses were beliefs about drinking for a typical college student and beliefs about drinking for a typical collegiate athlete.

Means and standard deviations for beliefs about peer weekly drinking at baseline and postintervention assessment by study condition and risk-status are shown in Table 1. Results of the repeated-measures ANOVA for beliefs about a typical college student's weekly drinking indicated a significant interaction effect for Time $\times$ Group $\times$ Risk-Status, Wilks's Lambda $=.90, F(3,47)=4.99, p=.03$, eta $^{2}=.10$. Follow-up analyses for typical college student drinking indicated that for high-risk student athletes, the reduction in beliefs about peer drinking reported in the WPF group was significantly different from the increase in beliefs about peer drinking reported in the WE group, Time $\times$ Group, Wilks's Lambda $=.75, F(1,15)=4.95$, $p=.04$, eta $^{2}=.25$. For low-risk student athletes, differences between baseline and postintervention beliefs about typical college student drinking were not significant between the two intervention groups. The repeated-measures ANOVA for beliefs about a typical collegiate athlete's weekly drinking was not significant. 
Table 1 Means and Standard Deviations for Perception of Peer Drinking at Preintervention and Postintervention Assessments by Study Condition and Drinking Risk Status

\begin{tabular}{llccc}
\hline \multicolumn{5}{c}{ Risk Status } \\
\hline Condition & Time & Low & Total \\
\hline \multirow{2}{*}{ Feedback } & Baseline & $21.40(7.79)$ & $14.73(7.54)$ & $17.40(8.19)$ \\
& Education & $17.10(8.37)$ & $17.07(11.07)$ & $17.08(9.88)$ \\
& Postintervention & $19.00(5.72)$ & $15.69(12.09)$ & $16.70(10.54)$ \\
& Baseline & $21.71(7.95)$ & $15.69(12.73)$ & $17.52(11.65)$ \\
\cline { 2 - 4 } Feedback & Postintervention & College Athlete Drinking \\
& Baseline & $12.90(6.85)$ & $6.64(5.09)$ & $9.25(6.56)$ \\
& Postintervention & $11.90(7.64)$ & $7.71(6.20)$ & $9.46(7.00)$ \\
& Baseline & $16.57(10.47)$ & $6.88(7.18)$ & $9.83(9.27)$ \\
& Postintervention & $16.29(9.21)$ & $6.56(6.78)$ & $9.52(8.69)$ \\
\hline
\end{tabular}

\section{Changes in Reported Alcohol Consumption}

Attrition. Overall, 64\% $(N=33)$ of the 52 participants completed both the 6 week and 3 month follow-up assessments. For this final sample, $46 \%(n=15)$ participants were in the WPF group and 54\% $(n=18)$ were in the WE group. There was no difference in the rate of attrition across the two intervention groups, $\chi^{2}=2.56, p=$ .15 or across the seminar sections, $\chi^{2}=7.34, p=.12$. A series of chi-square analyses revealed no differences in gender, $\chi^{2}=0.01, p=.98$, ethnicity, $\chi^{2}=0.87, p=.93$, or sport played, $\chi^{2}=4.62, p=.71$, between the participants who completed the program and those who did not. In addition, a series of independent sample $t$ tests indicated no differences in weekly drinking, $t(50)=0.64, p=.53$, peak drinking, $t(50)=1.20, p=.24$, or drinking to intoxication, $t(50)=1.77, p=.09$, between those who did or did not completed the program.

Alcohol Consumption. To examine whether student athletes classified as highrisk drinkers in the WPF group would report significantly greater reductions in drinking relative to those in the WE group, we conducted a repeated measures multivariate analyses of variance (MANOVA) using the same three independent variables as in the prior analyses. The three drinking measures included as dependent variables were quantity of weekly drinking, peak consumption, and drinking to intoxication.

Means for alcohol consumption measures at baseline, 6 week, and 3 month follow-up assessments by risk-status are shown in Table 2. Twenty-three percent of the student athletes reported no drinking across the three assessments. Results of the repeated-measures MANOVA indicated a significant interaction effect for Time $\times$ Group $\times$ Risk-Status, Wilks's Lambda $=.55, F(3,27)=3.23, p=.02$, eta $^{2}$ $=.45$. Follow-up univariate analyses of variance (using a Bonferroni-adjusted $\alpha$ of .01) revealed a significant Time $\times$ Group $\times$ Risk-Status interaction for weekly 
Table 2 Means and SD for Drinking Variables at Baseline, 6 Week, and 3 Month Follow-Up Assessments by Study Condition and Drinking Risk Status

\begin{tabular}{|c|c|c|c|c|}
\hline & & \multicolumn{3}{|c|}{ Risk Status } \\
\hline Condition & Time & High & Low & Total \\
\hline \multicolumn{5}{|c|}{ Weekly Drinking Quantity } \\
\hline \multirow[t]{3}{*}{ Feedback } & Baseline & $13.25(7.80)$ & $0.46(1.04)$ & $3.87(6.94)$ \\
\hline & 6 week & $9.50(4.73)$ & $1.64(2.77)$ & $3.73(4.82)$ \\
\hline & 3 month & $5.50(4.20)$ & $1.45(2.21)$ & $2.53(3.27)$ \\
\hline \multirow[t]{3}{*}{ Education } & Baseline & $8.17(7.63)$ & $0.58(1.38)$ & $3.11(5.65)$ \\
\hline & 6 week & $7.00(7.04)$ & $0.42(1.44)$ & $2.61(5.11)$ \\
\hline & 3 month & $8.17(7.60)$ & $0.67(2.02)$ & $3.17(5.73)$ \\
\hline \multicolumn{5}{|c|}{ Peak Alcohol Consumption } \\
\hline \multirow[t]{3}{*}{ Feedback } & Baseline & $11.75(2.75)$ & $1.09(1.64)$ & $3.93(5.23)$ \\
\hline & 6 week & $10.50(1.92)$ & $3.00(4.65)$ & $5.00(5.29)$ \\
\hline & 3 month & $7.00(4.76)$ & $2.64(4.03)$ & $3.80(4.52)$ \\
\hline \multirow[t]{3}{*}{ Education } & Baseline & $10.17(3.25)$ & $1.33(2.35)$ & $4.28(5.00)$ \\
\hline & 6 week & $10.67(3.78)$ & $1.92(2.81)$ & $4.83(5.23)$ \\
\hline & 3 month & $10.83(4.58)$ & $1.08(1.98)$ & $4.33(5.57)$ \\
\hline \multicolumn{5}{|c|}{ Drinking to Intoxication } \\
\hline \multirow[t]{3}{*}{ Feedback } & Baseline & $3.00(0.82)$ & $1.00(0.63)$ & 1.53 (1.13) \\
\hline & 6 week & $2.75(0.96)$ & $1.73(0.91)$ & $2.00(1.00)$ \\
\hline & 3 month & $1.50(0.58)$ & $1.82(0.98)$ & $1.73(0.88)$ \\
\hline \multirow[t]{3}{*}{ Education } & Baseline & $2.67(1.21)$ & $1.17(0.39)$ & $1.67(1.03)$ \\
\hline & 6 week & $2.50(1.23)$ & $1.25(0.45)$ & $1.67(0.97)$ \\
\hline & 3 month & $2.67(0.82)$ & $1.17(0.39)$ & $1.67(0.91)$ \\
\hline
\end{tabular}

drinking, $F(2,30)=4.85, p<.01$, eta ${ }^{2}=.14$, peak alcohol consumption, $F(2,30)=$ $5.01, p<.01$, eta $^{2}=.15$, and frequency of drinking to intoxication, $F(2,30)=7.30$, $p<.001, e t a^{2}=.20$. As predicted, for weekly drinking, peak alcohol consumption, and frequency of drinking to intoxication, high-risk student athletes in the WPF group reported they had reduced their drinking significantly more than those in the WE control group, while reported changes in drinking between the groups were similar for low-risk student athletes (see Figure 1).

Perceptions of Peer Drinking and Alcohol Use. To determine if reductions in beliefs about typical student drinking postintervention were related to reductions in drinking reported at 3 month, change scores were calculated for beliefs about typical student drinking and each of the three drinking variables. Only changes in beliefs about typical student drinking were examined as there were no significant changes in beliefs about typical athlete drinking at the postintervention assessment. Bivariate correlations indicated changes in beliefs about typical student drinking from baseline to postintervention were positively related to reported reductions in weekly drinking, peak consumption, and drinking to intoxication from baseline to the 3 month assessment for the WPF group only (see Table 3). 

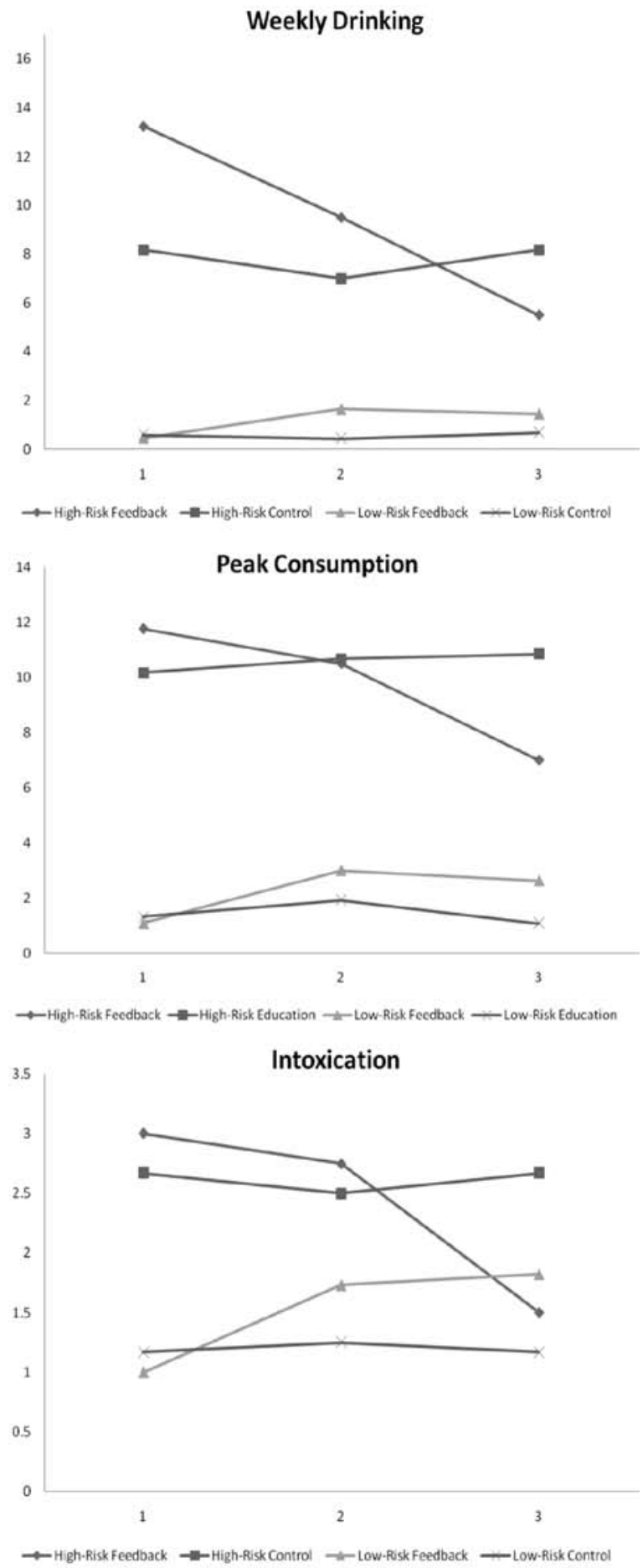

Figure $1-$ Changes in drinking by risk status and study condition. 
Table 3 Correlations Among Beliefs About Peer Drinking and Alcohol Consumption by Study Condition

\begin{tabular}{lcccc}
\hline & $\mathbf{1}$ & $\mathbf{2}$ & $\mathbf{3}$ & $\mathbf{4}$ \\
\hline \multicolumn{4}{c}{ Web-Based Personalized Feedback } \\
\hline 1. Weekly drinking & - & & \\
2. Peak alcohol consumption & $.74^{*}$ & - & & \\
3. Drinking to intoxication & .47 & .38 & - & \\
4. Beliefs about peer drinking & $.69^{*}$ & $.70^{*}$ & $.65^{*}$ & - \\
\hline \multicolumn{5}{c}{ Web-Based Education } \\
1. Weekly drinking & - & & \\
2. Peak alcohol consumption & -.24 & - & & \\
3. Drinking to intoxication & $.65^{*}$ & -.25 & - & \\
4. Beliefs about peer drinking & -.32 & .01 & -.04 & - \\
\hline
\end{tabular}

$* p<.01$.

\section{Discussion}

The aim of this study was to evaluate the efficacy of a Web-based personalized feedback program in the prevention of high-risk drinking for freshman student athletes. Although research indicates Web-based personalized feedback is effective for reducing high-risk drinking in college students (see Larimer \& Cronce, 2007; Walters et al., 2005; Walters \& Neighbors, 2005), this is the first study to provide evidence for using web-based personalized feedback as a promising strategy for reducing drinking in high-risk intercollegiate athletes. Thus, this study adds to the growing body of literature supporting the efficacy of Web-based personalized feedback programs and identifies an intervention strategy that effectively reduced drinking for high-risk students in this sample of freshman intercollegiate athletes.

Results indicated freshman student athletes reported both typical student athletes and typical college students drink more than they do. The direction and magnitude of the means were consistent with research indicating athletes believe their teammates drink more than they do and that typical college students drink more than their teammates (Dams-O'Connor et al., 2007; Thombs, 2000). Findings also supported the hypothesis that high-risk student athletes receiving personalized information would adjust their beliefs about peer drinking downward. For high-risk athletes, changes in beliefs about student drinking were reduced in the WPF group relative to the WE group. There were, however, no differences in the two groups in beliefs about athlete peer drinking levels. One explanation for this finding is that student athletes might have been less likely to change their beliefs about student athlete drinking because that group is more salient for them than typical college students. This is consistent with research indicating exposure to a social norms campaign was associated with athletes changing drinking estimates about general students but not estimates about their closest friends' drinking (Thombs, 2002). Alternatively, because the intervention provided information regarding college student drinking, rather than student athlete drinking, it is not surprising that changes in estimates were evident for college student drinking but not for student athlete drinking. Future 
research comparing programs providing normative data for typical college students vs. typical student athletes should be conducted to examine differential effects of types of normative feedback on subsequent drinking reductions.

Results of this study also confirmed the hypothesis that the reductions in drinking in the WPF group would be significantly greater than reductions in the WE group for high-risk athletes. High-risk student athletes in the WPF group reported greater reductions in weekly drinking, peak alcohol consumption, and frequency of drinking to intoxication than those in the WE condition, whereas changes in drinking for low-risk student athletes were similar across the two conditions. Highrisk student athletes in the WPF group reported nearly a $60 \%$ reduction in weekly drinking quantity, $40 \%$ reduction in peak drinking levels, and $50 \%$ reduction in frequency of drinking to intoxication compared with no reductions in drinking levels in the WE group at the 3-month follow-up. These findings are consistent with research indicating that Web-based personalized feedback programs are effective in reducing heavy drinking in college students (Chiauzzi, et al., 2005; Kypri et al., 2004; Neighbors et al., 2004; Walters et al., 2007). In addition, the finding that web-based feedback was most effective for freshman student athletes classified as high-risk drinkers parallels the college student literature. Specifically, the majority of research examining Web-based programs in college students has demonstrated efficacy in students identified as high-risk drinkers (Chiauzzi et al., 2005; Kypri et al., 2004; Neighbors et al., 2004; Walters et al., 2007) or indicates reductions in drinking are greater in high-risk drinkers (Bersamin et al., 2007) and persistent binge drinkers (Chiauzzi et al., 2005).

Results also indicated reductions in estimates of typical college student drinking from baseline to postintervention were associated with reductions in drinking at 3 months for the WPF group but not for the WE group. These results are consistent with previous research using change score correlations to demonstrate that changes in social norms were related to changes in drinking (Martens et al., 2007) and research on Web-based feedback programs that indicate reductions in drinking are mediated by reductions in estimates of peer drinking (Neighbors et al., 2004; Walters et al., 2007). Because of the small sample in this study, we were not able to directly test whether changes in beliefs about peer drinking mediated drinking reductions. However, because of the temporal relationship between the variables, the findings suggest reductions in drinking at 3 months may have been impacted by reductions in estimates of peer drinking that occurred immediately following the intervention.

Although this study adds to the literature by providing evidence for the efficacy of a web-based personalized feedback program for decreasing drinking in high-risk freshman student athletes, there are several limitations. First, seminar sections were randomly assigned to the two intervention conditions. Thus, athletes were actually nested within seminars. In future studies, random assignment of individual athletes, rather than seminar sections should be conducted. In addition, small sample size and attrition rate in this study limit the generalizability of the results. Although approximately $90 \%$ of freshman student athletes participated in this study, only $64 \%$ of those completed both follow-up assessments. Although attrition and selection are important issues to consider, a high percentage of athletes did participate in 
this study and there were no differences in any demographic or drinking variables between those who did or did not complete the study. Further, attrition rates were similar across study conditions, suggesting attrition was not related to the particular study condition. Future research with larger samples is recommended to replicate the findings in this study.

In addition, because $23 \%$ of the student athletes reported no drinking across the three assessments, the distributions for the drinking variables were relatively skewed. Although ANOVA models are quite robust to the violation of normality (Leech, Barrett, \& Morgan, 2005), future research with larger samples could exclude abstainers. Information in this study was also obtained through self-report. Although self-report potentially leads to biased or distorted reporting, self-reported alcohol use is common practice in college studies and research indicates the reliability of self-report is adequate (Marlatt et al., 1998). In addition, although the standard definition for binge drinking (Weschler et al., 1994) was used to define risk status, the NIAAA has recommended modifying this definition to specify a 2-hr timeframe, theoretically leading to a BAC of $0.08 \%$ (NIAAA, 2004). Although we did not include this timeframe, we believe drinking 4 or 5 drinks in a row in the last 2 weeks does represent high-risk drinking and students drinking this amount were correctly classified as high-risk drinkers.

Finally, the duration of the 3 month follow-up was fairly short. Although effects of Web-based personalized feedback programs have been shown to last for up to 6-months in college students (see Carey et al., 2007), future research should examine the efficacy of Web-based programs implemented for freshman athletes across a longer period of time. In addition, research indicates student athletes may drink more during the spring term relative to the fall term (Doumas et al., 2007), suggesting the importance of assessing the impact of the Web-based prevention program across the academic year. Research also indicates there are differences in athlete drinking patterns during the in-season and off-season, (Martens, DamsO'Connor, \& Duffy-Paiement, 2006; NCAA, 2001; Thombs, 2000) and across sports (Martens, Watson, et al., 2006, NCAA, 2001), suggesting future studies with larger samples should include season and sport played in investigations of the effectiveness of Web-based feedback programs.

This study represents an initial step in evaluating the efficacy of Web-based personalized feedback for freshman intercollegiate athletes and has important implications for developing alcohol prevention programs for this population. Although student athletes remain a high-risk population for drinking and alcohol-related problems, very few controlled studies have evaluated the impact of prevention programs targeting collegiate athlete drinking (see Larimer \& Cronce, 2007; Martens, Dams-O'Connor, \& Beck, 2006; Turissi et al., 2006). In addition, although research has demonstrated that personalized normative feedback programs are effective in decreasing alcohol use in the college student population (see Carey et al., 2007; Larimer \& Cronce, 2007), this is the first study to examine the efficacy of a Web-based personalized feedback program for intercollegiate athletes. Results of this study suggest providing a Web-based personalized feedback program during the fall semester of the freshman year is a promising strategy for the reduction of heavy drinking in the student athlete population. 


\section{References}

Abbey, A. (2002). Alcohol-related sexual assault: A common problem among college students. Journal of Studies on Alcohol. Supplement, 14, 118-128.

American Psychiatric Association. (2000). Diagnostic and Statistical Manual of Mental Disorders, Fourth Edition (DSM-IV). Washington, DC: APA.

Baer, J.S., Stacy, A., \& Larimer, M. (1991). Biases in the perception of drinking norms among college students. Journal of Studies on Alcohol, 54, 54-60.

Bersamin, M., Paschall, M.J., Fearnow-Kenney, M., \& Wyrick, D. (2007). Effectiveness of a web-based alcohol-misuse and harm-prevention course among high- and low-risk students. Journal of American College Health, 55, 247-254.

Bruce, S., \& Crockett, A. (2007). APPLE: A comprehensive student athlete substance abuse prevention model. Program presented at the U.S. Department of Education National Meeting on Alcohol and Other Drug Abuse and Violence Prevention in Higher Education, Omaha, NE.

Bruce, S., \& Sisk, K. (2006). APPLE: A comprehensive approach to promoting student athlete wellness and substance abuse prevention. The Peer Educator, 8-9.

Carey, K.B., Scott-Sheldon, L.A.J., Carey, M.P., \& DeMartini, K.S. (2007). Individual-level interventions to reduce college student drinking: A meta-analytic review. Addictive Behaviors, 32, 2469-2494.

Chiauzzi, E., Green, T.C., Lord, S., Thum, C., \& Goldstein, M. (2005). My Student Body: A high-risk drinking prevention web site for college students. Journal of American College Health, 53, 263-274.

Collins, R.L., Parks, G.A., \& Marlatt, G.A. (1985). Social determinants of alcohol consumption: The effects of social interaction and model status on the self-administration of alcohol. Journal of Consulting and Clinical Psychology, 53, 189-200.

Cooper, M.L. (2002). Alcohol use and risky sexual behavior among college students and youth: Evaluating the evidence. Journal of Studies on Alcohol. Supplement, 14, 101-117.

Cunningham, J.A., Humphreys, K., \& Koski-Jannes, A. (2000). Providing personalized assessment feedback for problem drinking on the internet: A pilot project. Journal of Studies on Alcohol, 63, 794-798.

Dams-O'Connor, K., Martin, J., \& Martens, M.P. (2007). Social norms and alcohol consumption among intercollegiate athletes: The role of athlete and nonathlete reference groups. Addictive Behaviors, 32, 2657-2666.

Doumas, D.M., \& Hannah, E. (2008). Preventing high-risk drinking in youth in the workplace: A web-based personalized feedback program. Journal of Substance Abuse Treatment 34, 263-271.

Doumas, D.M., Turrisi, R., Coll, K.M., \& Haralson, K. (2007). High risk drinking in college athletes and nonatheltes across the academic year. Journal of College Counseling, 10, 163-174.

Giacobbi, P.R., Lynn, T.K., Wetherington, J.M., Jenkings, J., Bodendorf, M., \& Langley, B. (2004). Stress and coping during the transition to university for first- year female athletes. The Sport Psychologist, 18, 1-20.

Grossman, S.J., Gieck, J.H., Freedman, A., \& Fang, W.L. (1993). The athletic prevention programming and leadership education (APPLE) model: Developing substance abuse prevention programs. Journal of Athletic Training, 28, 137-144.

Grossman, S.J., \& Smiley, E.B. (1999). APPLE: Description and evaluation of a substance abuse education and prevention program for collegiate athletics. The Journal of Primary Prevention, 20, 51-59. 
Hildebrand, K., Johnson, D.J., \& Bogle, K. (2001). Comparison of patterns of alcohol use between high school and college athletes and non-athletes. College Student Journal, $35,358-365$.

Hingson, R.W., Heeren, T., Zakocs, R.C., Kopstein, A., \& Wechsler, H. (2002). Magnitude of alcohol-related mortality and morbidity among U.S. college students ages 18-24. Journal of Studies on Alcohol, 63, 136-144.

Knight, J.R., Wechsler, H., Kuo, M., Seibring, M., Weitzman, E.R., \& Schuckit, M. (2002). Alcohol abuse and dependence among U.S. college students. Journal of Studies on Alcohol, 63, 263-270.

Kypri, K., Saunders, J.B., \& Gallagher, S.J. (2003). Acceptability of various brief intervention approaches for hazardous drinking among university students. Alcohol and Alcoholism (Oxford, Oxfordshire), 38, 626-628.

Kypri, K., Saunders, J.B., Williams, S.M., McGee, R.O., Langley, J.D., Cashell-Smith, M.L., et al. (2004). Web-based screening and brief intervention for hazardous drinking: A double-blind randomized controlled trial. Addiction (Abingdon, England), 99, 1410-1417.

Larimer, M.E., \& Cronce, J.M. (2007). Identification, prevention, and treatment revisited: Individual-focused college drinking prevention strategies 1999-2006. Addictive Behaviors, 32, 2439-2468.

Leichliter, J., Meilman, P., Presley, C., \& Cashin, J. (1998). Alcohol use and related consequences among students with varying levels of involvement in college athletics. Journal of American College Health, 46, 257-262.

Leech, N.L., Barrett, K.C., \& Morgan, G.A. (2005). SPSS For intermediate statistics: Use and interpretation (2nd ed.). Mahwah, NJ: Lawrence Erlbaum.

Marcello, R.J., Danish, S.J., \& Stolberg, A.L. (1989). An evaluation of strategies developed to prevent substance abuse among student-athletes. The Sport Psychologist, 3, 196-211.

Marlatt, G.A., Baer, J.S., Kivlahah, D.R., Larimer, M.E., Quigley, L.A., et al. (1998). Screening and brief intervention for high-risk college student drinkers: Results from a two-year follow-up assessment. Journal of Consulting and Clinical Psychology, 66, 604-615.

Martens, M.P., Cimini, D.M., Barr, A.R., Rivero, E.M., Vellis, P.A., Desemone, G.A., et al. (2007). Implementing a screening and brief intervention for high-risk drinking in university-based health and mental health care settings: Reductions in alcohol use and correlates of success. Addictive Behaviors, 32, 2563-2572.

Martens, M.P., Dams-O'Connor, K., \& Beck, N.C. (2006). A systematic review of college student-athlete drinking: Prevalence rates, sport-related factors, and interventions. Journal of Substance Abuse Treatment, 31, 305-316.

Martens, M.P., Dams-O'Connor, K., \& Duffy-Paiement, C. (2006). Comparing off-season with in-season alcohol consumption among intercollegiate athletes. Journal of Sport and Exercise Psychology, 28, 502-510.

Martens, M.P., Watson, J.C., \& Beck, N.C. (2006). Sport-type difference in alcohol use among intercollegiate athletes. Journal of Applied Sport Psychology, 18, 136-150.

Miller, W.R., \& Rollnick, S. (2002). Motivational interviewing: Preparing people to change addictive behavior (2nd ed.). New York, NY: Guilford Press.

National Collegiate Athletic Association. (2001). NCAA study of substance use habits of college student-athletes. Indianapolis, IN: NCAA.

National Institute on Alcohol Abuse and Alcoholism (2003). "Task Force on Recommended Questions of the National Council on Alcohol Abuse and Alcoholism: Recommended Sets of Alcohol Consumption Questions, October 15-6, 2003. 
National Institute on Alcohol Abuse and Alcoholism. (2004). National Institute of Alcohol Abuse and Alcoholism Council approves definition of binge drinking. NIAAA Newsletter, 3, 3 .

Neighbors, C., Larimer, M.E., \& Lewis, M.A. (2004). Targeting misperceptions of descriptive drinking norms: Efficacy of a computer-delivered personalized normative feedback intervention. Journal of Consulting and Clinical Psychology, 72, 434-447.

Nelson, T.F., \& Wechsler, H. (2001). Alcohol and college athletes. Medicine and Science in Sports and Exercise, 15, 287-291. Perkins, H.W. (2002). Social norms and the prevention of alcohol misuse in collegiate contexts. Journal of Studies on Alcohol, $14 S, 164-172$.

Perkins, H.W., \& Craig, D.W. (2006). A successful social norms campaign to reduce alcohol misuse among college student-athletes. Journal of Studies on Alcohol, 67, 880-888.

Saunders, J.B., Kypri, K., Walters, S.T., Laforge, R.G., \& Larimer, M.E. (2004). Approaches to brief intervention for hazardous drinking in young people. Alcoholism, Clinical and Experimental Research, 28, 322-329.

Thombs, D.L. (2000). A test of the perceived norms model to explain drinking patterns among university student athletes. Journal of American College Health, 49, 75-83.

Thombs, D.L., \& Hamilton, M. (2002). Effects of a social norm feedback campaign on the drinking norms and behavior of Division I student-athletes. Journal of Drug Education, 3, 227-244.

Turrisi, R., Mallett, K.A., Mastroleo, N.R., \& Larimer, M.E. (2006). Heavy drinking in college students: Who is at risk and what is being done about it? The Journal of General Psychology, 133, 401-421.

Walters, S.T., Miller, E., \& Chiauzzi, E. (2005). Wired for wellness: e-Interventions for addressing college drinking. Journal of Substance Abuse Treatment, 29, 139-145.

Walters, S.T., \& Neighbors, C. (2005). Feedback interventions for college alcohol misuse: What, why, and for whom? Addictive Behaviors, 30, 1168-1182.

Walters, S.T., Vader, A.M., \& Harris, T.R. (2007). A controlled trial of web-based feedback for heavy drinking college students. Prevention Science, 8, 83-88.

Wechsler, H., Davenport, A., Dowdall, G., Moeykens, B., \& Castillo, S. (1994). Health and behavioral consequences of binge drinking in college: A national survey of students at 140 campuses. Journal of the American Medical Association, 272, 1672-1677.

Wechsler, H., Lee, J.E., Kuo, M., \& Lee, H. (2000). College binge drinking in the 1990s: A continuing problem. Results of the Harvard School of Public Health 1999 College Alcohol Study. Journal of American College Health, 48, 199-210.

Wechsler, H., \& Nelson, T.F. (2001). Binge drinking and the American college student: What's five drinks? Psychology of Addictive Behaviors, 15, 287-291.

Wechsler, H., \& Nelson, T.F. (2006). Relationship between level of consumption and harms in assessing drink cut-points for alcohol research: on "Many college freshmen drink at levels far beyond the binge threshold" by White et al. Alcoholism, Clinical and Experimental Research, 30, 922-927.

Vik, P.W., Carrello, P., Tate, S.R., \& Field, C. (2000). Progression of consequences among heavy-drinking college students. Psychology of Addictive Behaviors, 14, 91-101.

Manuscript submitted: September 21, 2007

Revision received: February 18, 2008 
Copyright of Sport Psychologist is the property of Human Kinetics Publishers, Inc. and its content may not be copied or emailed to multiple sites or posted to a listserv without the copyright holder's express written permission. However, users may print, download, or email articles for individual use. 